\title{
trabalhonecessário
}

issn: $1808-799 \mathrm{X}$

ano 7 - número 8 - 2009

\section{Reformas da educação superior no Chile no período 1970-2000}

Ângela Siqueira - angelasiqueira@predialnet.com.br

O objetivo desse texto é mostrar as mudanças havidas na educação superior chilena, no período de 1970 a 2000, a partir da eleição e deposição do governo Allende, evidenciando a influência dos Estados Unidos e das organizações multilaterais no contexto econômico, político, social, cultural, educacional local, destacando o papel do Banco Mundial nas propostas das reformas da educação superior.

\section{O contexto sócio-político-econômico das reformas:}

A reforma do sistema de educação superior chileno começou logo após o golpe militar em 1973, que para sua consecução contou com grande apoio do Governo estadunidense e dos organismos internacionais, associados a grupos nacionais chilenos, como será mostrado a seguir.

A vitória nas urnas do socialista de Salvador Allende para a presidência do Chile em 1970 foi visto como uma grande ameaça intelectual e econômica para a expansão e manutenção da hegemonia dos Estados Unidos da América do Norte (EUA) e do ocidente, não só na América Latina, como também no mundo. Num documento secreto $^{2}$ liberado no final dos anos 1990, o Embaixador estadunidense no Chile, Edward Korry afirmou:

O Chile votou serenamente para ter um estado Marxista-leninista. A primeira nacão no mundo a fazer essa escolha livremente e conscientemente.... É um fato triste... Ele terá um efeito profundo na América Latina e além dela: nós sofremos uma severa derrota: as conseqüências serão domésticas e internacionais. (DEPARTMENT OF STATE. U.S. Embassy Cables, 5 de Setembro, 1970, p. 1-2, ênfase da autora).

\footnotetext{
1 Parte do texto sobre as reformas no Chile foi publicado anteriormente no artigo "As más lições da experiência. Reformas do ensino superior no Chile, na China e no Brasil" e são parte de Tese de doutorado da autora.

${ }^{2}$ Todas citações em português de textos originais em língua inglesa foram feitas pela autora, que tentou ser o mais fiel possível aos originais.
} 


\section{trabalhonecessário}

issn: $1808-799 \mathrm{X}$

ano 7 - número 8 - 2009

A manifestação estadunidense não terminou com a nota do Embaixador explicitando ser a eleição de Allende uma "severa derrota". Uma operação secreta objetivando evitar que Allende tomasse posse ou para depô-lo caso assumisse, foi decidida em uma reunião na Casa Branca, realizada no dia 15 de setembro de 1970, contando com a presença do então Presidente estadunidense Richard Nixon, o Advogado Geral John Mitchell, o Conselheiro Nacional de Segurança Henry Kissinger, e Richard Helms, Diretor Geral da Agência Central de Inteligência (CIA). Um dos objetivos mencionados na reunião foi o de "sufocar a economia chilena" (CIA, 1970, 15 de Setembro).

Em outro memorando, o então chefe da divisão da CIA para o hemisfério ocidental, William Broe, descreveu uma reunião convocada pelo Diretor da CIA e oficiais do alto escalão do serviço de inteligência:

O diretor disse ao grupo, que o Presidente Richard Nixon decidiu que um governo de Allende no Chile, não seria aceitável para os Estados Unidos. $O$ Presidente solicitou a Agência (CIA) que evitasse que Allende chegasse ao poder, ou que fosse retirado do mesmo. O Presidente autorizou para este fim, se necessário, a quantia de dez milhões de dólares. Mais ainda, a Agência deveria desenvolver essa missão sem qualquer vínculo com os Departamentos de Estado ou de Defesa. (CIA, 1970, 16 de Setembro)

Nesse ínterim, o Embaixador estadunidense no Chile reconheceu a influência de um grupo de economistas que preparam um relatório objetivando atrair os militares e convencê-los a apoiar o Presidente Eduardo Frei, que ainda estava no cargo, e evitar o reconhecimento pelo Congresso Nacional de Allende como o Presidente eleito:

A ação que iria colocar os militares apoiando o governo seria um relatório à Nação, feito esta semana pelo Ministro das Finanças, Andres Zaldivar. Ele e seu associado mais direto, o Ministro da Economia, Carlos Figueroa, vêm ostensivamente preparando nos últimos dias um relatório "técnico" sobre a situação da economia... Eles receberam ajuda de uma equipe de economistas em cada setor da economia. Todos os participantes nesse "estudo" são ligados por um único vínculo... sua total oposição a Allende. A motivação para o Relatório Zaldivar seriam os seus efeitos verdadeiramente destrutivos. (DEPARTMENT OF STATE. U.S. Embassy Cables, 1970, Setembro, p.14, ênfase da autora). 


\section{trabalhonecessário}

issn: $1808-799 \mathrm{X}$

ano 7 - número 8 - 2009

Como vai ser visto mais adiante, esses economistas vão desempenhar um papel fundamental no retorno do (neo)liberalismo no nível institucional dos governos e agências multilaterais, e na sociedade em geral.

Além da influência da equipe econômica, a ação secreta da CIA encorajou os golpistas e abasteceu-os com armas, granadas e munição (CIA, 1970, 17 de Outubro; CIA, 1970, 18 de Outubro).

O uso da propaganda também foi uma arma muito importante para denegrir a imagem de interna e externa do governo Allende, e justificar a idéia de um golpe de Estado para depô-lo, via o "condicionamento de pensamentos e ações" (CIA, 1970, 18 de Novembro, p.5). A propaganda intencionava alcançar tanto a sociedade chilena, como a comunidade mundial e assim tinha uma ampla abordagem, como está explicitado no Relatório sobre a Força Tarefa da CIA no Chile:

A CIA montou uma campanha de propaganda em torno do "El Mercurio"...Recursos da atividade secreta foram utilizados para enviar: telegramas de apoio/protesto de jornais de projeção ao "El Mercurio"; uma moção de protesto da Imprensa Internacional Associada (IPA)... 'Liberdade de imprensa no Chile está sendo estrangulada por Comunistas, marxistas e seus aliados'; Cobertura da imprensa internacional sobre a moção de protesto da IPA...; [infiltração de] 15 jornalistas - na verdade agentes - de 10 países distintos e mais 8 jornalistas... sob a direção de agentes de alto escalão...; a [criação] de uma imprensa marrom... [com] com distribuição por mala direta; colocação de notícias... por agentes...; financiamento de um novo jornal; subsídio a grupos políticos anti-Allende, bem como seus programas de rádio, suas propagandas políticas e manifestações públicas e encaminhamento de mala direta de artigos estrangeiros.

A magnitude da campanha de propaganda montada no período de seis semanas na mídia Latino Americana e Européia... indica como retornos parciais 726 artigos, transmissões de TV, editoriais e outros itens similares como resultados diretos das atividades dos agentes. "Briefings" especiais feitos pela inteligência e "in loco" foram distribuídos a jornalistas estadunidenses... Cabe destacar nessa conexão a matéria de capa da Time. (CIA, 1970, 18 de Novembro, p.9-11)

Apesar de todas essas atividades secretas, Allende foi confirmado como Presidente eleito no dia 24 de outubro de 1970. O Departamento de Estado e o 


\section{trabalhonecessário}

issn: $1808-799 \mathrm{X}$

ano 7 - número 8 - 2009

Conselho de Segurança Nacional estadunidense avaliaram a situação e propuseram algumas medidas. Em sua avaliação era esperado que:

O governo de Allende deve trabalhar contra os interesses estadunidenses no hemisfério e no resto do mundo.... Buscará influenciar outros países latinoamericanos a seguir o exemplo chileno. Ao mesmo tempo, o Chile deverá se tornar um céu para os subversivos latino-americanos e uma base para os movimentos subversivos de outros países. O governo Allende estabelecerá relações e re-estabelecerá todos os laços comerciais com Cuba...[assim como irá] reconhecer e estabelecer relações diplomáticas com outros países socialista, incluindo o Vietnam do Norte, a China Comunista, a Coréia do Norte e a Alemanha Oriental. Um governo Allende-marxista no poder representa um perigo em potencial para a segurança do hemisfério ocidental. (DEPARTMENT OF STATE, 1970, 3 de Novembro, p.4-5, ênfase da autora)

O mesmo documento indicou como os Estados Unidos deveriam agir daí por diante:

[O] exercício competente de nossa influência pode ser feito através da exacerbação das diferenças entre os elementos moderados e radicais da coalizão de Allende e também do incentivo àquelas forças que se opuseram ao estabelecimento de um governo marxista-leninista... [É mais importante que] trabalhemos para controlar as ações e ao mesmo tempo negando flexibilidade a Allende.... é também do interesse estadunidense tornar clara para o Chile e toda a América Latina, bem como para a União Soviética e para o mundo, a oposição dos Estados Unidos a um regime comunista na América Latina. (DEPARTMENT OF STATE, 1970, 3 de Novembro, p.7-13)

Em relação às ações para o estrangulamento na economia chilena anteriormente mencionadas pelo Presidente Richard Nixon ("make the [Chilean] economy scream"), os Estados Unidos deveriam usar sua influência sobre as organizações financeiras internacionais, como o Banco Mundial, o Fundo Monetário Internacional e o Eximbank, de maneira a reduzir os recursos destinados ao Governo Chileno, e, ao mesmo, torná-los mais disponíveis para outros países na região.

Não apoiar re-escalonamento do débito chileno; vetar os pedidos de empréstimos do Chile ao Banco Mundial, Banco Interamericano de Desenvolvimento, Eximbank...; desencorajar investimentos privados estadunidenses, de outros países ou multilaterais no Chile; desencorajar o turismo e viagens para o Chile; não dar qualquer assistência às linhas aéreas chilenas, nenhum equipamento novo; manter relações efetivas com os militares 


\section{trabalhonecessário}

issn: $1808-799 \mathrm{X}$

ano 7 - número 8 - 2009

chilenos; incentivar nos aliados da OTAN a necessidade de que apoiassem os interesses de segurança do hemisfério ocidental; no caso do Chile vir a desenvolver laços de segurança com a União Soviética aumentar dramaticamente a cooperação com outros países da América do Sul (oferecer para vender F-4s para a Argentina em termos favoráveis, fornecer especial MAP material [sic] para Argentina e Brasil, apoiar a posição da Argentina no Canal de Beagle, aumentar a ajuda internacional para segurança (MAP e segurança pública) no Uruguai, Paraguai, e possivelmente Bolívia); fornecer ajuda coordenada, pública e privada, a uma base democrática no Chile em oposição ao regime de Allende, através de meios apropriados; divulgar continuamente as restrições às liberdades individuais e fraquezas de um regime comunista; continuar o programa PL 489 (sic) e a utilização do fundo especial de desenvolvimento do Embaixador; Incentivara as principais nações sulamericanas a demonstrar uma firme oposição a uma ameaça de um Chile comunista; ...sugerir aos governos da Argentina, Brasil e Paraguai que eles também devem dar seu suporte aos militares chilenos; utilizar a OEA [Organização dos Estados Americanos] para apontar violações chilenas aos seus mandatos e resoluções. (DEPARTMENT OF STATE, 1970, 3 de Novembro, p.14-18)

Em setembro de 1973, um golpe militar depôs Allende da Presidência do Chile, e o General Augusto Pinochet assumiu o cargo. As primeiras medidas adotadas pelo regime ditatorial foi a eliminação de opositores e reformas econômicas. A situação dos direitos humanos no Chile, no período de 11 de setembro a 15 de novembro de 1973, foi assim descrita pelo próprio Departamento de Estado dos EUA:

Total de pessoas presas: 13.500; execuções, de acordo com as forças de inteligência: 320; mortos em tentativa de fuga da custódia militar: 40; total de mortos segundo cabo [comunicação] da CIA de 21 de outubro: de 2 a 3000; evadidos do Chile: aproximadamente 2.000; número de salvo condutos expedidos: 4.891; salvo condutos não atendidos: 408; registrados no UNHRC [Alto Comissariado das Nações Unidas para os Direitos Humanos] para imigração definitiva: 2.019. (DEPARTMENT OF STATE, 1973, 15 de Novembro, p.5)

O mesmo documento afirmou que a economia do país estava numa situação econômica lastimável e a política do governo Pinochet estava sofrendo muitas críticas:

O custo de vida aumentos 88 por cento em outubro [de 1973].... [Esse] aumento era previsto em decorrência de deixar que os preços artificialmente controlados buscassem seus valores reais, gerando um período de dificuldades econômicas que teve um grande impacto nos grupos de baixa e média renda. Como 


\section{trabalhonecessário}

issn: $1808-799 \mathrm{X}$

ano 7 - número 8 - 2009

resultado, a dura política econômica de estabilização do governo está sob críticas de vários locais...; a queda de liquidez e o crescimento do desemprego levantam o medo da recessão. (DEPARTMENT OF STATE, 1973, 15 de Novembro, p.3)

Nesse contexto e para resolver a crise, governo estadunidense mudou drasticamente o seu comportamento em relação às restrições econômicas e políticas impostas ao Governo Chileno nos três anos anteriores, isto é, durante o governo Allende, passando a usar todo seu poder e influência para ajudar o novo governo ditatorial chileno, com perdão de parte da dívida, re-escalonamento de outra parte e novos empréstimos:

Assumindo que um perdão da dívida de cerca de $\$ 350$ milhões possa ser obtida junto ao Clube de Paris e outros credores, o déficit da balança comercial poderia ser reduzido para $\$ 450$ milhões. De acordo com os chilenos, bancos privados estadunidenses e canadenses já prometeram $\$ 171$ milhões em novos empréstimos. O FMI também deve fornecer ... \$43 milhões até o final do ano.... Outros recursos devem estar por vir da Europa Ocidental, Japão, Brasil e Argentina.... No dia 14 de novembro nós anunciamos nosso segundo... crédito para o Chile - \$ 24 milhões. (DEPARTMENT OF STATE, 1973, 15 de Novembro, p.3-4)

No mesmo período, a insatisfação dos países em desenvolvimento (ou periféricos) também estava crescendo, não só em ralação as intervenções contra a soberania dos países, mas também em relação às regras comerciais na economia mundial, rebaixando o valor de seus produtos (em maioria sua maioria commodities), ampliando seus déficits comerciais, dependência e pobreza.

Nesse sentido cabe destacar a criação da Organização dos Países Produtores de Petróleo (OPEP) e a tentativa de obtenção de um valor considerado mais justo por tal produto nas transações comercias; a atuação do Grupo dos 77 (G-77) ${ }^{3}$, que também mostrou alguma força ao conseguir aprovar sua proposta para uma nova ordem econômica mundial na Assembléia Geral da ONU em maio de 1974, bem como ao introduzir modificações no Acordo Geral sobre Comércio e Tarifas (GATT), no que

\footnotetext{
${ }^{3}$ grupo de países pobres e em desenvolvimento criado no âmbito Organização das Nações Unidas (ONU), no início dos anos 1960, em contraposição ao grupo dos países ricos (G-7).
} 


\section{trabalhonecessário}

issn: $1808-799 \mathrm{X}$

ano 7 - número 8 - 2009

se refere ao amparo legal para as demandas desses países em relação ao tratamento especial e diferenciado, contrariando os interesses dos países mais ricos.

Os países produtores de petróleo, em sua maioria pobres e em desenvolvimento, perceberam que o processo de industrialização, em especial nos países ricos, tinha como sua base fundamental o uso do petróleo; portanto, eles poderiam explorara essa dependência mundial na commodity que produziam e tentar obter um melhor preço. Com base nessa premissa e na fundação da OPEP esses países conseguiram valorizar sua commodity e o preço do barril de petróleo sofreu grandes aumentos, o primeiro em 1973 (passando de US\$ 2.70 para US\$11.20) e mais tarde, em 1979, (de US\$ 18.60 para US\$ 30.50). Os aumentos do preço do petróleo implicaram no crescimento dos débitos existentes, bem como na ampliação dos déficits nas balanças de pagamento.

A Declaração de uma Nova Ordem Econômica Global, aprovada em primeiro de maio de 1974, na Assembléia Geral da ONU, expressou as preocupações com a situação econômica e relação entre os países, e defendeu os princípios de eqüidade, soberania das nações, igualdade, interdependência, interesse comum e cooperação mútua entre todos os países:

Os vestígios ainda existentes de dominação colonial e estrangeira, atividades de grupos, pessoas e empresas estrangeiras, discriminação racial, apartheid $e$ novas formas de colonialismo persistem como alguns dos grandes obstáculos para a plena emancipação e crescimento dos países em desenvolvimento e todas as populações envolvidas. Os benefícios dos avanços tecnológicos não são igualmente compartilhados entre os membros da comunidade internacional. Os países em desenvolvimento que representam 70 por cento da população mundial, contam com apenas 30 por cento dos recursos financeiros mundiais.... O bem estar político e econômico das gerações atuais e futuras depende cada vez mais da cooperação entre todos os membros da comunidade internacional, tendo por base o respeito à soberania [igualdade de soberania] e o fim dos desequilíbrios existentes entre eles. (UNITED NATIONS, 1974)

Esses princípios também foram defendidos na Rodada do Uruguai do GATT, iniciada em 1973 e concluída em 1979. Nessas negociações vários artigos da nova regulamentação reconheceram os problemas e os interesses dos países mais pobres e em desenvolvimento, permitindo o tratamento especial e diferenciado. Contudo, assim 


\section{trabalhonecessário}

issn: 1808-799X

ano 7 - número 8 - 2009

como a Declaração de 1974, aprovada na ONU, essas mudanças no âmbito do GATT acabaram sendo muito mais uma vitória moral do que uma mudança real nas negociações comerciais, visto que, como explica Williams (1994, p.148) "como as negociações geralmente se dão entre fornecedores e consumidores, e os países mais pobres raramente são responsáveis por grandes transações comerciais, os representantes dos países da OCDE tem sido os participantes mais ativos nas negociações do GATT".

Enquanto os países pobres e em desenvolvimento estavam se articulando e elaborando propostas, os grupos dominantes ligados ao comércio, aos negócios e finanças internacionais também se articularam, fortalecendo os think tanks estadunidenses como o Council of Foreign Affairs e a Brookings Institution, que em 1973, ajudaram a fundar a Comissão Trilateral. Essa Comissão, fundada dentre outros por David Rockefeller, presidente do Banco Chase Manhattan e por Zbigniew Brzezinski, conselheiro de segurança do Presidente estadunidense Jimmy Carter, tinha como objetivo criar uma parceria duradoura entre as classes dirigentes da América do Norte, Europa Ocidental e Japão. Seus membros provinham do setor comercial e bancário internacional, dos governos, academia, mídia e trabalhadores conservadores. (SKLAR, 1980, p.2)

Além da Comissão Trilateral, cabe ainda mencionar a Fundação Heritage, também criada no mesmo ano, porém mais conservadora. Também foi criado um grupo para aproximar e fortalecer as elites das três Américas, denominado "Americas Society", cuja origem vem do Conselho para as Américas, que é vinculado ao já mencionado Council of Foreign Affairs.

O aumento do preço do petróleo afetou seriamente a economia dos países ricos, além de mostrar certo poder e organização dos países pobres. A Comissão Trilateral uma saída comercial e financeira para a crise, que consistiria na canalização nos recursos recebidos pelos países da OPEP, os petrodólares, principalmente para o Banco Mundial, que iria emprestar aos países em desenvolvimento, que por sua vez teriam recursos para comprar os bens exportados pelos países industrializados (FRIEDEN, 1980). 


\section{trabalhonecessário}

issn: $1808-799 \mathrm{X}$

ano 7 - número 8 - 2009

O crescimento dos movimentos sociais desde o final dos anos 1960 , foi visto pelos grupos dominantes como um problema de "excesso de democracia", como mencionado pelo professor Samuel Huntington, um professor da Universidade de Harvard e membro da Comissão Trilateral (SKLAR, 1980, p.37).

Nesse contexto, em que muitos apoiavam medidas de melhor distribuição de renda, poder decisório, menos desemprego, melhores condições de trabalho, maior controle sobre os monopólios e seus efeitos nocivos, como poluição, mortes e degradação ambiental; Outros, os mais ricos, queriam a redução da participação das pessoas comuns nas decisões e também o fim das regulamentações dos Estados que impunham limitações aos seus negócios, como por exemplo, algumas leis trabalhistas, impostos e normas ambientais.

Assim, houve um resgate dos princípios liberais do século XVIII, que serviram para justificar que todos os problemas eram decorrentes da intervenção do governo na economia, que criou grandes déficits com seu gigantismo e gastos excessivos. Mais ainda, as demandas dos grupos mais pobres e oprimidos exigiam mais recursos através do aumento de impostos. Nesse contexto, a solução proposta pelos países e grupos mais ricos foi a redução da intervenção e do tamanho do Estado, restringindo qualquer excesso de democracia, deixando as forças de mercado agir livremente, pois assim resolveriam todos os problemas.

A concessão do Prêmio Nobel de Economia, a Milton Friedman e Friederich Hayek, ambos defensores do livre mercado, da "livre" escolha, contra qualquer regulamentação do Estado à livre circulação do capital e que ampliasse ou estabelecesse direitos aos trabalhadores, respectivamente m 1974 e 1976 não pode ser visto como uma simples coincidência. $\mathrm{Na}$ verdade, deve ser vista como uma chancela acadêmica sobre o valor "científico" dos estudos. Essa chancela foi amplamente explorada pela mídia, cada vez mais concentrada e controlada por alguns poucos conglomerados, para convencer os povos, associações e governos sobre a validade das premissas e projetos decorrentes dessa perspectiva econômica liberal, mudando sua visão de mundo e de sociedade, a fim de encampar como suas as propostas desejadas e fomentadas pelos grupos economicamente dominantes. $\mathrm{O}$ 


\section{trabalhonecessário}

issn: $1808-799 \mathrm{X}$

ano 7 - número 8 - 2009

trabalho de convencimento das elites dirigentes locais era de fundamental importância para as reformas e o processo de expansão e acumulação capitalista:

O meio mais eficaz de promover a abertura dos mercados é, sem dúvida, é ter uma elite ocidentalizada, interessada no desenvolvimento econômico, que esteja disposta a promovê-lo independente dos efeitos negativos para a vasta maioria dos cidadãos do seu país. Isso tem sido muito bem feito.... As elites do Terceiro Mundo são de fato nossos [países ricos] representantes nos países em que elas são dominantes (GOLDSMITH, 1996, p.257).

Ainda em relação ao convencimento da população e elites locais, Caufield (1996) relata a existência do que ela denominou "porta giratória", significando o intercâmbio de altos executivos em postos nos governos e no Banco Mundial. Por exemplo, ela menciona que um dirigente Turco, Attila Karaosmanoglu, que em seu país exercia um cargo de planejamento estatal, entrou para o Banco Mundial em 1966 e depois, em 1971 voltou ao seu país para ser o primeiro ministro (CAUFIELD, 1996, p.196). Ainda em relação à Turquia, ela destaca que o primeiro presidente que sucedeu o regime militar em 1983, Turkut Ozal, havia sido um executivo do Banco Mundial que preparou o plano de ajuste econômico do país (Ibidem, p.147). Caufield também descreve um processo similar na Índia em que tanto o ex-secretário de finanças, Montek Singh Ahluwalia, como o principal consultor econômico e também principal negociador do país, Shankar Achya, foram ex-executivos do Banco Mundial, sendo que Achya tirou licença de sua posição no Banco (Ibidem, p.196). Na Venezuela, Moises Naim, ex-ministro da indústria, também foi um ex-executivo e diretor do Banco (Ibidem, p. 215). Ela também revela que:

Entre os executivos do Banco que ocuparam cargos nos últimos anos em distintos governos estão Henry Konan Bedie, presidente da Costa do Marfim; Nicephore Soglo, presidente do Benin; Jose Cordoba Montoya, considerado o segundo homem mais importante na administração do presidente mexicano Carlos Salinas de Gortari [ele mesmo um pós-graduado em Harvard]; e Pedro Malan, ministro das finanças do Brasil. . (CAUFIELD, 1996, p.196)

Nesse contexto, todas as pessoas, grupos ou países que demonstrassem preocupação com questões sociais, trabalhistas ou com o meio ambiente eram imediatamente taxados de jurássicos, retrógrados, dinossauros, pré-históricos, etc. 


\section{trabalhonecessário}

issn: $1808-799 \mathrm{X}$

ano 7 - número 8 - 2009

As críticas existentes sobre o Banco Mundial e seus empréstimos, no sentido de que seus projetos não estavam gerando crescimento econômico, mas sim beneficiando os grupos mais ricos com muitas obras de grande porte e, ao mesmo tempo depredando o meio-ambiente, com aumento de poluição, crescimento de doenças decorrentes do uso de agrotóxicos e outros produtos químicos, aumentando o débito etc., foram taxados pelos representantes dos países ricos como mau uso dos recursos por governos e administradores irresponsáveis, pródigos e preguiçosos. Dessa forma, houve uma forte pressão para que o Banco mudasse sua atuação e a lógica de concessão de seus empréstimos. Assim, a partir da década de 80, o Banco Mundial assumiu um novo papel, que foi delineado em reunião realizado na Brookings Institution (FRIED e OWEN, 1982), onde previa sua atuação não mais como agente do desenvolvimentismo-dependente, mas sim como entidade articulada com o FMI para proceder os ajustes necessários a fim de assegurar o pagamento da dívida, que foi gerada como meio necessário para reciclar os petrodólares acumulados nos bancos americanos, principalmente o Citibank e o Chase Manhatan Bank, e pela posterior alta nas taxas de juros decidida unilateralmente pelos EUA, a fim de conter a queda do dólar em 1979.

Com a administração da dívida externa e os empréstimos para os ajustes estruturais e, mais acentuadamente na década de 90, após a queda do Muro de Berlim, o Banco Mundial aumentou sua influência direta e indireta sobre grande parte dos países, em especial os mais endividados, como México, Brasil e Argentina, na América Latina.

O Chile, contando com forte apoio dos economistas da Universidade de Chicago, em especial de Milton Friedman, foi o primeiro país a adotar, de modo institucional, o "novo" ideário econômico, ou neoliberal, antecedendo e servindo de exemplo, para o que veio a acontecer como "ajuste econômico" em outros países, já sob pressão da atuação conjunta Banco Mundial-FMI.

A seguir vamos mostrar alguns aspectos da institucionalização do pensamento neoliberal no Chile e o sentido das reformas propostas. 


\section{trabalhonecessário}

issn: $1808-799 \mathrm{X}$

ano 7 - número 8 - 2009

\section{A Influência da Escola de Chicago e A Reforma do Estado Chileno}

Desde 1955, segundo Collins e Lear (1995), alguns chilenos, com o apoio das famílias das classes média e alta, assim como dos empresários, e mais tarde da Aliança para o Progresso e do próprio governo democrata-cristão chileno, trouxe alguns economistas estadunidenses da Universidade de Chicago. O grupo de economistas de Chicago era liderado por Theodore Schultz e, incluía também Milton Friedman. O objetivo do grupo consistia em reformar o currículo da educação superior, bem como criar um centro de pesquisas econômica no país, o que foi feito através de um convênio com a Universidade Católica do Chile. O convênio ente a Universidade de Chicago e a Católica do Chile implicava também na garantia de recursos para que alguns economistas chilenos pudessem fazer seus estudos de pós-graduação em Chicago. Outra característica importante do convênio foi a mudança do currículo de economia adotado no Chile, com a introdução programas de estudos da teoria do preço, a ênfase em disciplinas como estatística, cálculos de custo benefício e análises de regressão, comércio internacional, e, ao mesmo tempo a redução de outras disciplinas como história econômica, sociologia e história chilena.

Valdés (1995) em seu trabalho sobre a influência da Escola de Chicago no Chile entrevistou Rolf Luders, um membro do grupo de economistas que trabalhou em oposição ao Governo Allende e, este declarou que "Aproximadamente cem alunos fizeram seus estudos de pós-graduação na Universidade de Chicago no início dos anos setenta... Muitos deles tornaram-se professores, outros trabalharam no Governo [Eduardo] Frei - que antecedeu Allende - e outros foram para trabalhar em empresas chilenas" (VALDÉS, 1995, p.18).

Como Collins e Lear (1995) revelaram, no dia do golpe de estado, esses economistas e seus apoiadores estavam imprimindo o plano de reforma econômica chilena. O plano era tão volumoso que foi apelidado de "o tijolo".

Contudo, esses economistas formados em Chicago, a maioria jovens das classes mais abastadas, com sua formação liberal monetarista, ainda não tinham conseguido angariar a total confiança dos militares chilenos. Cabe destacar que a prioridade do governo militar foi a de promover uma ampla limpeza ideológica. Assim, 


\section{trabalhonecessário}

issn: $1808-799 X$

ano 7 - número 8 - 2009

apesar de inicialmente o plano elaborado por tais economistas não ter sido imediatamente implementado, suas idéias passaram a circular em todos os setores decisórios e influenciaram o grupo mais tradicional dos economistas, que ainda endossavam o pensamento econômico liberal de matriz keynesiana.

Quando parte do Partido Cristão-Democrata e seus economistas tornaram-se céticos em relação ao autoritarismo de Pinochet e deixaram o governo, os novos economistas entraram no governo. Esses economistas, conhecidos como os "Chicago Boys" (garotos de Chicago) começaram a implementar as idéias (neo)liberais no Chile e, mais tarde, como consultores, ajudaram a disseminá-las pelo mundo.

A influência do pensamento econômico de Chicago no governo ditatorial chileno pode ser vista na posição ocupada por alguns dos "Chicago Boys" e outros economistas tradicionais, convertidos ao credo monetarista (neoliberal), nos altos escalões do governo Chileno:

Sergio Castro- Ministro da Economia (1975-76) e depois Ministro das Finanças (1976-1982); Pablo Baraoona- Ministro da Economia (1976-1988); Rolf LüdersMinistro das Finanças (1982-1983); Alvaro Bardón, Sub-Secretário Economia na gestão de Baraona; Miguel Kast- Ministro do Planejamento (1982). Outros economistas de Chicago menos conhecidos ocuparam vários postos no Banco Central, no Escritório de Planejamento e em outras divisões de planejamento do governo. Esses economistas incluem: Juan Carlos Meúndez, Alvaro Donoso, Ernesto Silva Bafalluy, Jorge Selume, Alvaro Seich, etc. As posições ideológicas do grupo de Chicago foram compartilhadas por economistas de prestígio, anteriormente vinculados aos Cristões-Democratas. Dentre eles o mais notável foi Jorge Cauas, pós-graduado na Columbia University, que foi Ministro das Finanças e aplicou o "choque" econômico; e José Piñera, pós-graduado em Harvard, que foi o último Ministro do Trabalho e que implantou as reformas sociais. (VALDÉS, 1995, p.19)

Milton Friedman reconheceu essa influência do pensamento de Chicago no Chile, como pode ser visto na citação a seguir, feita por Frazer (1988), com base num artigo de 1982 do próprio Friedman intitulado "Free markets and the generals":

$\mathrm{Na}$ tentativa de retificar a situação [a crise econômica divulgada como decorrente do regime socialista de Allende], os militares adotaram um amplo plano para uma economia do livre mercado que foi preparado por um grupo de jovens economistas chilenos, em sua maioria, ex-alunos da Universidade de Chicago. Nos primeiros dois anos, os denominados "Chicago boys" participaram 


\section{trabalhonecessário}

issn: $1808-799 \mathrm{X}$

ano 7 - número 8 - 2009

na implementação do plano, mas em posições subalternas, havendo pouco sucesso na inflação. De algum modo, em desespero, a junta [militar] delegou o poder aos "Chicago boys"... e o milagre econômico estava a caminho (FRAZER, 1988, p.338).

O vínculo e a influência da Escola de Chicago, em especial de Milton Friedman, no regime militar e na sociedade chilena podem ser vistas num artigo publicado em 1976, num jornal chileno, de autoria de Jonathan Kendell, mencionado Frazer:

Santiago, Chile - Não é comum que a um famoso economista, com posições bem definidas, seja dada a oportunidade de testar prescrições específicas para uma economia muito doente. É ainda mais incomum quando o cliente desse economista é um país que não o seu próprio.

Milton Friedman, professor da Universidade de Chicago, alcançou precisamente esse status no Chile. Dificilmente se passa uma semana sem uma referência a esse seu status no Chile. Dificilmente se passa uma semana sem uma referência ao seu nome ou as suas teorias nos jornais e revistas. A maioria dos membros do grupo dos economistas da junta [governo militar] estudou com Milton Friedman ou consideram-se como "Chicago Boys," discípulos dos princípios conservadores monetaristas do professor.

A visão do Sr. Friedman sobre a economia do Chile tem sido amplamente apoiada pelo Departamento de Estado dos Estados Unidos, homens de negócios e banqueiros internacionais, bem como um notável grupo de organizações internacionais, como o Banco Mundial, o Banco Interamericano de Desenvolvimento e o Fundo Monetário Internacional. (FRAZER, 1988, p.351352)

No mesmo artigo, Kandell também mencionou uma viagem que Friedman fez ao Chile, em 1975, financiada por banqueiros, em que ele apontava como solução para a crise chilena "reduzir o número excessivo de funções e empregos no governo, vender empresas públicas deficitárias para o setor privado, reduzir a emissão de moedas e restringir o crédito" (FRAZER, 1988, p.353).

Vale destacar que, apesar de todo o discurso e reformas enfatizando os benefícios do livre mercado, da privatização, da desnacionalização e da redução do tamanho do Estado, matindos se preciso com o uso da força para impor medidas drásticas e limitar a oposição, a junta militar chilena manteve as minas de cobre, a maior fonte de recursos e principal produto de exportação do país, como propriedade estatal e intocada por essa medidas liberalizantes 


\section{trabalhonecessário}

issn: $1808-799 \mathrm{X}$

ano 7 - número 8 - 2009

Em uma outra citação do livro de Frazer (1980), Milton Friedman sumariza seu "milagre econômico":

A inflação foi reduzida de 700 por cento em meados de 1984, para menos de 10 por cento ao ano. Após uma transição difícil, a economia floresceu, crescendo a uma média de 8 por cento ao ano de 1976 a 1980. Os salários reais e o emprego aumentaram rapidamente e o desemprego caiu. Importações e exportações dispararam depois que muitos subsídios foram eliminados e as tarifas reduzidas para 10 por cento... Muitas empresas públicas foram desnacionalizadas e a área de transporte e outras foram desregulamentadas. Um sistema de voucher (vales) foi implantado na educação elementar e secundária. A mais notável de todas, foi a reforma da seguridade social adotada que permite que os indivíduos escolham entre participar do sistema pública ou contribuir para sua própria aposentadoria de forma privada (FRAZER, 1988, p.350).

Contudo essa visão otimista de Friedman, apesar de alguns "sucessos"econômicos, parece ter gerado graves problemas sociais, como pode ser visto no relatório de desenvolvimento humano, elaborado pelo PNUD, de 1997, que apresenta uma descrição das reformas chilenas, baseadas no plano de estabilização dos Chicago Boys e na perspectiva do livre mercado, bem como seus resultados econômicos e sociais:

Essas reformas incluíram a liberação do comércio, das taxas de câmbio e das contas de capital, reestruturação dos impostos, liberalização do sistema financeiro, privatização e profundas reformas trabalhistas (não havendo sindicatos, negociações coletivas ou normas trabalhistas até 1979).

Os benefícios em termos de crescimento demoraram um pouco a aparecer. A economia passou por grandes conturbações e interrupções nos anos 1970, severa recessão em 1982, e o crescimento sustentável ocorreu pós 1986. O crescimento da exportação ficou entre 5,7 por cento ao ano entre 1980 e 1990, e 10.5 por cento ao ano entre 1990-94. Contudo a UNCTAD [no Estudo anual sobre economia e desenvolvimento social da ONU de 1996] nota que ... a maioria das exportações chilenas se concentrava em produtos de baixa elasticidade de crescimento e de preço, e em alguns casos o Chile estava perdendo mercado. Os efeitos na distribuição foram também notáveis. $O$ coeficiente Gini, aumentou de 0,46 do final dos anos 1960 para cerca de 0,56 em $1994 \ldots$ ampliando a distribuição de renda....

O desemprego era muito elevado: o desemprego aberto atingiu 19.2 em 1982, e o desemprego, incluindo aqueles beneficiados por programas públicos de emprego chegou a 30,3 por cento em 1983. O processo de privatização vem sendo criticado por ter contribuído para aumentar a concentração [e 


\section{trabalhonecessário}

issn: $1808-799 \mathrm{X}$

ano 7 - número 8 - 2009

desnacionalização]: por exemplo, os novos fundos de pensão privados são pertencem a quatro grupos internacionais.

Estima-se que a pobreza aumentou de 17 por cento em 1970 para 45 por cento em 1985...

Dados da CEPAL indicam que a pobreza reduziu um pouco no período 1987-90 (de 38,2 para 34,5 por cento)... [Outro estudo em 1996, de Ravallion e Chen, utilizando uma outra linha de pobreza] sugere que esse declínio continuou no período $1990-1992 \ldots$ de 20,25 para 10,5 por cento.

[ em relação aos ] gastos sociais... até meados de 1970 os programas sociais tinham um caráter universal, mas o governo subseqüente adotou um instrumento nacional de seleção, o cartão de estratificação social, que definiu o acesso aos programas do Estado. [Com] o grande grau de focalização... os gastos sociais vêm caindo (de 22 por cento do total do gasto público em 1983, para 15 por cento em 1992).

Relatórios do governo dos anos 1970 e 1980 indicaram o aumento de doenças ligadas às condições sanitárias dos alimentos e de vetores transmitidos através do sistema digestivo, particularmente tifo e hepatite. Houve também um aumento da desnutrição, infecções cutâneas, alcoolismo, dependência de drogas, problemas mentais e doenças relacionadas ao trabalho... O crescimento dos planos de saúde privados que acompanharam a reforma da previdência social aumentaram as diferenças nos indicadores dos tratamentos de saúde... Outros aspectos preocupantes incluem o aumento da criminalidade... e a... concentração e forte investimento de capital em alguns [poucos] produtos de exportação, como minerais e frutas. . (BERRY, HORTON AND MAZUMDAR, 1997, p.63-64)

Após a decisiva influência dos Chicago Boys no Chile, a equipe neoliberal permaneceu sendo constituída por muitos pós-graduados em universidades estadunidenses, principalmente de Harvard e Chicago, mas também de Michigan, Boston, MIT, etc. Silva (1994) menciona vários integrantes do governo Patrick Alwin, que sucedeu a ditadura Pinochet, indicando sua instituição de formação: Alexandro Foxley- Ministro das Finanças, Wisconsin; Pablo Piñera- Vice-Ministro de Finanças, Boston; José Pablo Arellano- Diretor de Orçamento, Harvard; Javier EtcheverriaDiretor de Arrecadação, Michigan; Manuel Marfón- Coordenador de Política Financeira, Yale; Jorge Marshall- Vice-Minister de Assuntos Econômicos, Harvard; Alejandro Jadresic- Coordenador das Políticas Econômicas Setoriais, Harvard; Fernán IbáñezSecretário de Investimentos Externos, MIT; Andrés Sanfuentes- Presidente do Banco do Estado, Chicago; Eduardo Arnant- Coordenador da Dívida Externa, Harvard; Roberto Zahler- Consultor do Banco Central, Chicago. (SILVA, 1994, p.223) 


\section{trabalhonecessário}

issn: $1808-799 \mathrm{X}$

ano 7 - número 8 - 2009

Nesse contexto é que devem ser entendidas as reformas na educação superior chilena que serão apresentadas a seguir.

\section{A(s) Reforma(s) da Educação Superior no Chile nos anos de neoliberalismo}

Nos anos 1980s ocorreram mudanças significativas no sistema de ensino superior chileno, implementadas através de vários decretos presidenciais com a força de lei (DFL - Decreto con Fuerza de Ley).

Cabe destacar que a educação superior no Chile, com base na matriz espanhola, organizou-se em instituições universitárias. Assim sendo, até 1980, o sistema de ensino superior chileno era constituído por oito universidades: duas públicas e seis privadas; tanto as instituições públicas como as privadas recebiam grande suporte financeiro governamental. Os professores das universidades públicas faziam parte da categoria dos servidores públicos e tinham uma carreira, escala de pagamento e demais direitos assegurados ao funcionalismo público, como, por exemplo, a estabilidade. A maioria dos estudantes, $65 \%$, estava vinculada às universidades públicas (CASTAÑEDA, 1986, p. 18).

A primeira ação do regime ditatorial foi a de desvincular o salário do pessoal universitário do funcionalismo público em geral. Isto foi feito através do DFL $n^{\circ} .3$ da Educação, publicado em 31/12/1980, que estabeleceu que a remuneração fosse fixada no âmbito de cada universidade, conforme seus regulamentos internos.

Em 03/01/1981, foi publicado o DFL $n^{\circ} .1$ de 1980, que definiu o que seria a Universidade e listou 12 campos nos quais essas instituições deveriam oferecer diploma universitário: direito, arquitetura, bioquímica, odontologia, agronomia, engenharia, comércio (economia e administração), engenharia florestal, medicina, medicina veterinária, psicologia, e farmácia. As instituições universitárias foram as únicas instituições autorizadas a oferecer graus acadêmicos de Licenciado, Mestre e Doutor.

Em 07/01/1981 foi publicado o DFL n² de 1980, que estabeleceu um prazo de 90 dias para que os reitores das universidades apresentassem um plano de reestruturação visando reduzir o tamanho das mesmas. Assim, as duas universidades 


\section{trabalhonecessário}

issn: $1808-799 \mathrm{X}$

ano 7 - número 8 - 2009

públicas deveriam ser divididas, dando margem à criação de novas instituições de ensino superior a partir da reestruturação dos seus campi regionais.

Já o DFL n4, de 20/01/1981 estabeleceu 03 mecanismos de financiamento: 1) Aporte Fiscal Direto (AFD), baseado na porcentagem histórica atribuída às universidades e suas unidades regionais em 31/12/1980; 2) Aporte Fiscal Indireto $(\mathrm{AFI})$, baseado no número de matriculado em cada instituição, dentre os 20.000 estudantes com maior nota no teste acadêmico nacional; e 3) programa de crédito estudantil. A idéia subjacente à transferência indireta $(\mathrm{AFI})$, baseada nos estudantes com melhores resultados e os esquemas de crédito estudantil, era a de que as instituições deveriam competir para atrair/matricular estudantes. Porém, os esquemas de crédito foram restritos às instituições publicamente subsidiadas (universidades tradicionais - públicas e privadas - e as suas novas filiais) como um modo de compensar as mensalidades escolares.

Este mesmo DFL $n^{\circ}$. 4/81 estabeleceu algumas metas quanto à redução da transferência direta e ao aumento da transferência indireta. Era esperado que a transferência direta fosse reduzida de 14.152,6 milhões de pesos chilenos em 1980 para 7.076,3 milhões de pesos chilenos em 1986, enquanto que a transferência indireta chegasse a 7.076,3 milhões de pesos chilenos em 1986, e o crédito estudantil aumentasse dos 14.152,6 milhões de pesos chilenos em 1980 para 21.228,9 milhões de pesos chilenos em 1986 (CASTAÑEDA, 1986, p.43). Outra fonte de financiamento seriam as mensalidades escolares, que deveriam não só ser aumentadas, mas também diferenciadas por campo de saber (CASTAÑEDA, 1986, p.29).

Também em 1981, o DFL nº. 33 de Educação (MINEDUC, 2000) criou um fundo especial para desenvolvimento científico e tecnológico (FONDECYT - Fondo de Desarollo Científico y Tecnológico) que deveria funcionar em bases competitivas.

O aspecto organizacional da reforma de ensino superior Chilena foi complementado pela criação dos Institutos Profissionais - IPs (DFL $n^{0} .5$ de 16/02/1981) e dos Centros Treinamento Técnico - CTTs (DFL no. 24 de 16/04/1981). Os IPs deveriam priorizar o ensino, formando profissionais para trabalhar em campos específicos, concedendo títulos profissionais e técnicos. Os CTTs, voltados para servir 


\section{trabalhonecessário}

issn: $1808-799 \mathrm{X}$

ano 7 - número 8 - 2009

às escolas secundárias, deveriam enfatizar o treinamento prático em programas que não durassem mais do que 04 semestres e concederiam apenas títulos técnicos.

Com a introdução desses DFLs o número de instituições de ensino superior cresceu de 08 universidades, com 116.962 alunos matriculados em cursos de graduação em 1980 (CASTAÑEDA, 1986, p.18), para 261 instituições, com 184.434 alunos em 1984 (Ibidem, p.45). O novo sistema de ensino superior incluía 29 universidades e 8 institutos profissionais, subsidiados pelo estado, mais 3 universidades privadas, 25 institutos de profissional privados e filiais e 196 centros para treinamento técnico (Ibidem, p.44).

Em relação às matrículas por tipo de instituição de ensino superior, em 1983 (MINEDUC, 2001a) as universidades subsidiadas pelo Estado atendiam a $61,0 \%$ dos estudantes matriculados em cursos de graduação no país, e os institutos profissionais subsidiados pelo Estado, 10,2\%; enquanto que as universidades privadas, $3,1 \%$, os institutos profissionais privados, $4,3 \%$ e os centros para treinamento técnico, $23,0 \%$.

Em relação aos cursos oferecidos por campos de conhecimento, em 1983, os CTTs concentravam $74 \%$ de sua matrícula em duas áreas: administração e comércio (43\%) e tecnologia (34\%). Os IPs tinham $56 \%$ de sua matrícula em cursos de treinamento de professores para as séries iniciais da educação (outras áreas com nível significante de matrícula eram administração e comércio (15\%), e tecnologia (14\%). As Universidades Privadas tinham $79 \%$ de sua matrícula em 3 áreas: ciências sociais (35\%), direito $(27 \%)$ e administração e comércio (17\%). Já as universidades subsidiadas (as universidades tradicionais e suas novas "filiais") apresentavam $71 \%$ de suas matrículas em 4 áreas: tecnologia (32\%), educação (18\%), saúde $(13 \%)$ e ciências sociais (8\%) (MINEDUC, 2001a).

É importante ressaltar que cursos de pós-graduação (Mestrados e Doutorados) só podiam ser ministrados nas universidades tradicionais (MINEDUC, 2001a); quer dizer, as novas universidades privadas se limitavam ao ensino de graduação.

Como observou Castañeda (1986, p.26) as antigas universidades (ou universidades tradicionais) ofereciam cursos mais caros enquanto todas as outras instituições começaram a oferecer cursos mais baratos e lucrativos. 


\section{trabalhonecessário}

issn: $1808-799 \mathrm{X}$

ano 7 - número 8 - 2009

Quanto ao aspecto financeiro, as transferências fiscais efetivadas para educação superior ficaram longe da meta indicada para ser alcançada em 1985. Houve de fato uma redução da transferência direta em 52\% (de 14.153 milhões de pesos chilenos para 7.377 milhões de pesos chilenos), mas a transferência indireta, esperada que atingisse $7.076,3$ milhões de pesos chilenos não ultrapassou 1.183,3 milhões de pesos chilenos. Similarmente, o valor da transferência via créditos estudantis ficou abaixo do previsto: em vez de alcançar 21.228,93 milhões de pesos chilenos, foram desembolsados apenas 11.234,3 milhões de pesos chilenos (CASTAÑEDA, 1986, p.43 e 48).

No que concerne à dificuldade financeira das universidades tradicionais e filiais, as mesmas também foram afetadas por mudanças nas transferências indiretas: "[Em vez do] pagamento diferenciado por campo de estudo,... pagamento uniforme. Outra mudança foi a de que em vez de beneficiar os 20.000 estudantes com as maiores notas no teste nacional, foi estendido aos 27.000 melhores estudantes com maiores notas matriculados em cada universidade (CASTAÑEDA, 1986, p.31). Com todos os cursos recebendo o mesmo valor, independente dos seus custos diferenciados, as universidades privadas que ofereciam cursos menos dispendiosos acabavam por receber um pagamento relativamente maior para os seus cursos. Além disso, elas poderiam receber mais recursos através do aumento do número de estudantes matriculados com altos escores.

Contudo, como a pesquisa continuou sendo desenvolvida quase que exclusivamente nas universidades tradicionais, os fundos para desenvolvimento de pesquisa deveriam ser absorvidos por tais instituições. Porém, o DFL que criou os fundos de pesquisa, direcionou os recursos aos pesquisadores (indivíduos), ao invés das instituições, deixando uma diminuta porcentagem para as mesmas.

O modelo chileno de reforma da superior veio a ser defendido pelo Banco Mundial como o modelo a ser seguido. A grande diferenciação institucional junto com a diversificação do financiamento acarretaram na transferência de custos para a esfera privada (estudantes e suas famílias) através da cobrança de elevadas mensalidades 


\section{trabalhonecessário}

issn: $1808-799 \mathrm{X}$

ano 7 - número 8 - 2009

nas instituições públicas e privadas. Mas tal mudança não melhorou a qualidade e nem a eqüidade como prometido pelos defensores do livre-mercado.

Dados de admissões em 1989-1990 mostraram que embora a porcentagem de estudantes de baixo nível sócio-econômico era pequena dentro das universidades, tal porcentagem era menor nas novas universidades privadas do que nas tradicionais (publicamente subsidiadas). A proporção de alunos provenientes de famílias em que seus pais tinham ocupações de artesões autônomos, pequenos proprietários, trabalhadores manuais ou serviços domésticos era de 34,2\% nas universidades publicamente subsidiadas e de $24,8 \%$ nas universidades privadas. Por outro lado, $57 \%$ dos alunos matriculados nas instituições privadas vieram de famílias cujos pais eram gerentes, profissionais liberais, empresários, empregados especializados, enquanto que nas universidades públicas essa proporção era de 41\% (BRUNNER e BRIONES, 1992, p.44).

Além disso, o sistema da educação superior chileno estava oferecendo um número reduzido de cursos de pós-graduação stricto sensu (mestrado e doutorado), o que, por sua vez, estava afetando a disponibilidade de pessoal docente qualificado necessário para atuar nas inúmeras instituições de educação superior e atender ao grande número de alunos matriculados, assim como fomentar o desenvolvimento da pesquisa básica e aplicada. O baixo nível de qualificação docente, principalmente nas novas instituições privadas, permitiu e reforçou relações de trabalho baseadas em baixos salários e tempo parcial.

Como atesta documento do Banco Mundial, antes da reforma, o Estado financiava $100 \%$ dos custos do ensino superior, enquanto que em 1990 essa porcentagem caiu para 27\% (WORLD BANK, 1998, p.3, grifos nossos). Essa grande redução do suporte financeiro por parte governo à educação superior afetou drasticamente as universidades tradicionais, não só com o abandono dos serviços de manutenção e de infra-estrutura necessários, mas também com a redução dos salários do seu pessoal. Mais ainda, face à redução do apoio financeiro, as instituições, departamentos e professores foram impelidos a buscar recursos externos, vendendo serviços técnicos, fazendo consultorias, lecionando em outras instituições de educação 


\section{trabalhonecessário}

issn: $1808-799 \mathrm{X}$

ano 7 - número 8 - 2009

superior; em resumo, desenvolvendo um número crescente de atividades remuneradas fora da universidade. O engajamento em tais atividades externas afeta negativamente o tempo e qualidade que deveriam ser dedicados às atividades fundamentais nas universidades, tais como o ensino e a pesquisa, assim como os serviços de extensão não-lucrativos. Os professores em sua busca por recursos acabam por ter um período pós-classe insuficiente para manter trocas formais e informais com seus pares e alunos, assim como para participar plenamente na vida de sua instituição acadêmica. Além, disso alguns professores abandonaram as universidades públicas em busca de melhores salários (CIFUENTES, CUENCA E SALINAS, 1998).

Em 1990, o governo eleito pós-ditadura aprovou uma nova Lei Orgânica de Educação (Lei 18.956, conhecido como LOCE), reconhecendo a existência de três tipos de instituições (universidades, instituições profissionais e centros para treinamento técnico), e criando o Conselho Superior de Educação (Nacional). Este Conselho deveria ser o órgão responsável pela implantação de um sistema de credenciamento das Instituições de Ensino Superior. Contudo, somente os estabelecimentos criados depois da promulgação da LOCE seriam obrigados a passar pelo o novo processo de credenciamento. Com isso, a idéia do credenciamento como meio para melhorar a baixa qualidade de muitos cursos e instituições foi debilitada (MINEDUC, 2000).

O governo de 1990 declarou que o ensino superior seria uma prioridade, e introduziu algumas medidas para atenuar parte dos problemas de eqüidade e de qualidade gerados pela grande aderência à lógica do mercado: introdução de mudanças no programa de empréstimo estudantil visando aliviar, para pais e alunos, as dívidas já existentes; redução dos encargos nos novos empréstimos, e adoção de programas de bolsas de estudos, ampliando o apoio aos alunos. Assim, ao término de 1991 foi aprovada uma lei redefinindo o esquema original de empréstimos reembolsáveis, que até esta data representava a única forma de apoio aos estudantes. Já em 1993 a porcentagem desses empréstimos foi reduzida a 39\% dos recursos disponíveis para auxílio aos alunos, enquanto o programa de bolsas de estudos recebeu $35 \%$, um novo projeto visando reintegrar alunos evadidos obteve $3 \%$ desses 


\section{trabalhonecessário}

issn: $1808-799 \mathrm{X}$

ano 7 - número 8 - 2009

recursos e um outro projeto para o desenvolvimento institucional (FDI - Fondo de proyectos de desarollo institucional) recebeu 25\% (Lehman, mencionado por FANELLI, 1997, p.37).

Os governos pós-ditadura, preocupados com a fragmentação das instituições de ensino superior, disponibilizaram mais recursos para a pesquisa básica e aplicada, beneficiando mais diretamente as universidades tradicionais. Endossando ainda alguns princípios do mercado, novos fundos e programas deveriam ser criados tendo por base o princípio da competição. No período 1991-1996 três novos fundos foram criados: em 1991, um fundo para o incentivo de desenvolvimento científico e tecnológico (FONDEF - Fondo de Fomento al Desarollo Científico y Tecnológico); em 1992, um fundo para desenvolvimento institucional (PDI - Programa de Desarollo Institucional); e, em 1996, um fundo para o desenvolvimento de pesquisa avançada (FONDAP - Fondo de Desarollo de Areas de Investigación Avanzada) (FANELLI, 1997, p.39).

O Banco Mundial reconhece a mudança havida: "Desde o retorno da democracia em 1990, os recursos alocados ao sub-setor [ensino superior] aumentaram cerca de 50\% em termos reais... Em 1997, os recursos, nas instituições públicas e privadas, foram provenientes de, [respectivamente], mensalidades (33\%), renda de serviços (26\%), e subsídios públicos (41\%)" (WORLD BANK, 1998, p.3, grifos nossos).

Seguramente as medidas governamentais não foram suficientes para lidar com os problemas gerados pela expansão e diversificação descontroladas do ensino superior chileno. Em 1998, a quantidade de instituições de ensino superior era menor que o número existente no período do auge da reforma. Em vez dos 261 estabelecimentos de ensino superior existente em 1983, este número diminuiu para 252 em 1998. A maior redução foi no número de centros de treinamento técnico (administrados pelo setor privado) que caiu de 196 estabelecimentos em 1983 para 120 em 1998. O número de universidades subsidiadas pelo Estado permaneceu estável em 25, consistindo nas universidades tradicionais e nas instituições que emergiram das mesmas em função dos decretos com força-de-lei. Porém, houve um aumento significativo no número de universidades privadas, de 3 em 1983 para 41 em 1998, como também no número de institutos profissionais privados, de 25 em 1983 


\section{trabalhonecessário}

issn: $1808-799 \mathrm{X}$

ano 7 - número 8 - 2009

para 66 em 1998. Os institutos profissionais públicos foram absorvidos pelas universidades regionais (filiais das universidades tradicionais); assim, esse tipo de instituto profissional deixou de existir na esfera pública (MINEDUC, 2001a).

O expansionismo foi forte o suficiente para mudar a predominância da matrícula no nível de graduação das instituições publicamente subsidiadas (universidades tradicionais) para as instituições privadas. Enquanto em 1983 as instituições de ensino superior beneficiadas com as transferências diretas (universidades tradicionais) atendiam a $71,2 \%$ de todos os estudantes de graduação do país, em 1998 essa porcentagem caiu para 48\%. Assim, em 1998 as instituições privadas estavam atendendo a $52 \%$ dos estudantes de graduação do país, principalmente nas universidades $(22 \%)$ e institutos profissionais (16\%). Os centros para treinamento técnico apresentaram a mais baixa porcentagem de alunos matriculados: 14\% (MINEDUC, 2001a).

Resumindo, a expansão e diversificação do sistema de ensino superior chileno, aliadas à competição por alunos e fundos de pesquisa, não parece ter melhorado a qualidade da educação ou o acesso dos alunos provenientes de famílias de baixo nível sócio-econômico de modo como previsto e amplamente propagandeado pelos defensores locais do "livre" mercado e pelas instituições bancárias multilaterais. Esse grupo argumentava ainda que a competição pelos os melhores estudantes por parte das instituições públicas e privadas levaria a uma melhor distribuição de recursos, assim como a uma redução permanente dos gastos públicos com este setor. Contudo os dados aqui apresentados evidenciam que este não foi o caso.

De maio e a junho de 1997 manifestações estudantis espocaram no Chile. Em 1998, um novo projeto do Banco Mundial foi aprovado para o ensino superior chileno (WORLD BANK, 1998). O projeto criado visava "melhorar" a qualidade e eqüidade dentro do ensino superior e foi conhecido como MECE-SUP (Proyecto de Mejoramiento de la Calidad y Equidad de la Educación Superior).

Cabe destacar que no referido projeto há referências a certas alternativas de reforma que não foram aceitas pelo Banco, sinalizando, portanto, a existência de divergência entre as recomendações do Banco e as pretensões do governo chileno. 


\section{trabalhonecessário}

issn: $1808-799 \mathrm{X}$

ano 7 - número 8 - 2009

Algumas das alternativas negadas pelo Banco foram: investimentos em esquemas de empréstimo para estudantes; investimento direto em "inputs", tais como em equipamentos, edifícios e treinamento; e foco mais direto nas instituições de ensino superior regionais e menos desenvolvidas. Essas alternativas foram rejeitadas com base nos seguintes argumentos: o governo pode assumir, por si só, os custos decorrentes dos empréstimos aos estudantes; o financiamento direto para os "inputs" só aliviaria a situação, mas não encorajaria uma melhoria de desempenho; e, finalmente, o Banco desejava aumentar a diferenciação das instituições e programas do ensino superior e, um foco no regional poderia por em risco essa meta (WORLD BANK, 1998, p.12).

Os três principais componentes do projeto de ensino superior chileno foram: capacitação, garantia de qualidade e financiamento.

Por capacitação o Banco definiu o estabelecimento de um sistema de administração da informação, promoção de treinamento técnico e o fortalecimento do grupo MECE-SUP e da divisão de ensino superior, visando chegar "a um consenso" sobre a necessidade da reforma e do estabelecimento de um novo arcabouço legal para ensino superior. A garantia de qualidade foi explicitada como o desenvolvimento de um sistema de avaliação e credenciamento tanto em nível de graduação como de pós-graduação, e que seria executado por um "Conselho Nacional para Credenciamento e Avaliação". O item financiamento objetivava vincular a distribuição de recursos ao desempenho. Assim, as instituições deveriam receber recursos com base em um sistema de contrato. Os AFDs (transferências diretas) deveriam ser substituídos gradualmente por uma fórmula de alocação de recursos baseada no desempenho, enquanto os AFIs (transferências indiretas) deveriam ser descontinuados e seus recursos distribuídos através de um novo fundo competitivo. Esse Fundo "substituiria e aperfeiçoaria o atual Fundo de Desenvolvimento Institucional" (FDI) (WORLD BANK, 1998, p.2-7, anexo 2).

Dos 3 componentes, o item "financiamento" absorveria 94,2\% dos recursos. O foco principal dessa reforma parece ter sido o direcionamento dos recursos públicos das universidades tradicionais para o setor privado. Isso seria alcançado pelo uso dos 


\section{trabalhonecessário}

issn: $1808-799 \mathrm{X}$

ano 7 - número 8 - 2009

novos fundos competitivos. Em um dos cenários esperados e esboçados pelo Banco sobre os possíveis efeitos do novo fundo competitivo na distribuição de um FDI aumentado, haveria uma pequena redução na quantia dedicada às universidades do grupo das quatro grandes tradicionais (Universidad do Chile, Universidad Católica do Chile, Universidad de Santiago do Chile e Universidad de Concepción), que cairia de $29,2 \%$ para $21,8 \%$; o segundo grupo, das 21 universidades tradicionais, sofreria uma grande perda: de $70,8 \%$ para $43,1 \%$, sinalizando ainda a disponibilização desses recursos públicos para as demais instituições de ensino superior privadas nas seguintes proporções: novas universidades privadas $(18,7 \%)$, institutos profissionais $(10,6 \%)$ e centros para treinamento técnico (5,8\%) (WORLD BANK, 1998, p.10, anexo 4). No projeto, foi afirmado que benefícios adicionais poderiam ser disponibilizados via mudanças no desembolso dos AFDs (WORLD BANK, 1998, p.11). Havia ainda clara indicação de que empréstimos e subvenções seriam aumentados, gradualmente, principalmente para estudantes matriculados nos IPs e CTTs privados (WORLD BANK, 1998, p.16, anexo 4).

Esse projeto mostra a força dos grupos privados e dos defensores do "livre" mercado, objetivando usar o governo para financiar seus próprios negócios, enquanto que evitando regulamentações os custos e lucros dos seus empreendimentos.

\section{Considerações Finais}

Como foi visto ao longo do texto, as reformas da educação superior no Chile introduziram uma perspectiva de gestão empresarial/ de mercado, afetando sobremaneira os objetivos, o comportamento, a administração, a organização, o financiamento, o acesso, os cursos oferecidos, a definição e desenvolvimento de atividades de pesquisa, o referencial de avaliação do ensino superior, etc. Cabe frisar que tais reformas foram implantadas sob regime autoritário, com seu início durante o regime ditatorial de Pinochet, contando com forte suporte do Governo estadunidense, dos organismos internacionais, em especial do Banco Mundial, bem como das elites econômicas locais, grande parte formada em universidades estadunidenses e/ou compartilhando o pensamento econômico neoliberal. Nos últimos anos, e, em função 


\section{trabalhonecessário}

issn: $1808-799 \mathrm{X}$

ano 7 - número 8 - 2009

de pressão principalmente dos estudantes, algumas alterações superficiais vem sendo introduzidas, mas sem reverter a perspectiva mercadológica instalada.

\section{Bibliografia:}

BERRY, A., HORTON, S. e MAZUNDAR, D. (1997). Globalization, adjustment and poverty. In UNITED NATIONS DEVELOPMENT PROGRAMME (UNDP). Poverty and Human Development. Human Development Papers 1997. New York: UNDP, Human Development Report Office, p. 21-80.

BRUNNER, J. J. e BRIONES, G. (1992, Novembro). Higher education in Chile: effects of the 1980 reform. In L. Wolff and D. Albrecht (Eds.). Higher education reform in Chile, Brazil and Venezuela. Towards a redefinition of the role of the State. (A view of the LATHR, 34). Washington, D.C.: The World Bank, Human Resources Division, Technical Department, Latin American and Caribbean Region.

CASTAÑEDA, T. (1986, Julho). Innovations in the financing of education: the case of Chile. Report EDT 35. Washington, DC: The World Bank, Education and Training Department, Op. Policy Staff.

CAUFIELD, C. (1996). Masters of Illusion. The World Bank and the poverty of Nations. New York: Henry Holter and Company, Inc.

CAVANAGH, J., GERSHMAN, J., BAKER, K. e HELMKE, G. (Eds.). (1992). Trading freedom: how free trade affects our lives, work and environment. San Francisco: Institute for Food and Development Policy, Food First, Institute for Policy Studies. CENTRAL INTELLIGENCE AGENCY - CIA. (1970, 15 de setembro). On Chile. Handwritten notes from CIA Director Richard Helms in a White House meeting. Disponível on line em the National Security Archives website http://www.gwu.edu/ nsarchiv/NSAEBB/ NSAEBB8/ch26.

CIA. (1970, 16 de Setembro). Genesis of Project FUBELT. Memorandum for the record. William V. Broe, CIA Chief for the Western Hemisphere Division. Disponivel on line em the National Security Archives website http://www.gwu.edu/ nsarchiv/ NSAEBB/ NSAEBB8/ch03. 


\section{trabalhonecessário}

issn: $1808-799 \mathrm{X}$

ano 7 - número 8 - 2009

CIA. (1970, 17 de Outubro). Cable from Santiago to CIA Headquarters. Santiago 562. Disponível on line em the National Security Archives website http://www. gwu.edu/ $\sim$ nsarchiv/NSAEBB/ NSAEBB8/ch27

CIA. (1970, 18 de Outubro ). Cable from CIA Headquarters to Santiago. Ref. Santiago 562. Disponivel on line em the National Security Archives website http://www.gwu.edu/ $\sim$ nsarchiv/NSAEBB/NSAEBB8/ch28

CIA. (1970, 18 de Novembro). Report on CIA Chilean task force activities. 15 September to 3 November 1970. Disponivel on line em the National Security Archives website http://www.gwu.edu/ nsarchiv/NSAEBB/NSAEBB8/ch01.

CHILE. MINISTERIO DE EDUCACIÓN DE CHILE - MINEDUC (2000, Agosto). Marco Jurídico de la educación superior. Santiago, Chile: Servicio de información del Ministerio de Educación de Chile 1998-2000. Disponível on line no site http://www.mineduc.cl/superior/marco.htm.

CHILE.MINEDUC.(2001a). Compendio de Educación Superior. Santiago, Chile: Mineduc. Disponível on line no site http://www. mineduc.cl/superior/compendio.htm CHILE.MINEDUC.(2001b). MECESUP. Santiago, Chile: Mineduc. Disponível on line no site http://www. mineduc.cl/superior/mecesup

CIFUENTES, L., CUENCA, J. e SALINAS, R. (1998). En defensa de la univerisad estatal Chilena. Ciencia al Día. Santiago, Chile.

COLLINS, J. e LEAR, J. (1995). Chile's free market miracle: A second look. Oakaland, CA: Food First Book.

DEPARTMENT OF STATE. (1975, 15 de Novembro).Chilean executions. Briefing memorandum. Disponível on line em the National Security Archives website http://www.gwu.edu/ nsarchiv/NSAEBB NSAEBB8/ch10.

Executive Secretary. (1970, 3 de Novembro). Chile Options Paper. Washington, DC. Disponível on line em the National Security Archives website http://www.gwu.edu/ nsarchiv/NSAEBB/ NSAEBB8/ch24.

. U.S. Embassy Cables. (1970, 5 de Setembro). Allende wins.

Cable 3499. Santiago: U.S. Embassy. Disponivel on line em the National Security Archives website http:// www.gwu.edu / nsarchiv/NSAEBB/ NSAEBB8/ch18. 


\section{trabalhonecessário}

issn: $1808-799 \mathrm{X}$

ano 7 - número 8 - 2009

U.S. Embassy Cables. (1970, Setembro). Frei transacting the future. Cable 3824. Santiago: U.S. Embassy. Disponivel on line em the National Security Archives website http://www.gwu.edu/ nsarchiv/NSAEBB/NSAEBB8/ch16. FANELLI, A. M.G. (1994). "Universidad Nacional y Sector Productivo". In MOROSINI, M.C. (Ed.) Universidade no Mercosul. São Paulo: Cortez, p. 103-122.

FRIEDEN, J. (1980). The Trilateral Commission: Economics and politics in the 1970s. In SKLAR, H. (Ed.). Trilateralism. The Trilateral Commission and elite planning for world management. Boston, MA: South End Press.

FRIED, E. e OWEN, H.D. (Eds). (1982). The Future Role of The World Bank. Washington, D.C.: The Brookings Institution.

FRIEDMAN, M. (1962/1982). Capitalism and freedom. Chicago: University of Chicago Press.

FRIEDMAN, M. e FRIEDMAN, R. (1980). Free to choose. Chicago: University of Chicago Press.

GEORGE, S. (1992). The debt boomerang. How Third World debt harm us all. Boulder, Colorado: Pluto Press/ Transnational Institute.

GOLDSMITH, E. (1996). Development as colonialism. In MANDER, J. e GOLDSMITH, E. (Eds.). The case against the global economy. And for a return toward the local. San Francisco: Sierra Club.

HAYEK, F. A. VON. (1944/ 1994). The road to serfdom. Chicago: University of Chicago Press.

PURCELL, S. K. e ROETT, R. (1997). Brazil under Cardoso. Americas Society/ Lynne PSACHAROPOULOS, G. (1980, November). Higher education in developing countries: a cost-benefit analysis. Washington, DC: The World Bank, Staff Working Paper, n. 440. PSACHAROPOULOS, G., JIMENEZ, E. e TAN, J-P. (1986, Julho). Financing education in developing countries. Washington, D.C.: The World Bank, Education and Training Department/ Research Division.

RIVEROS, L. A. (1996). Crisis y renovación de la política universitaria del Estado. El modelo chileno. In DELFINO, J.A e GERTEL, H.R. (Eds) Nuevas direcciones en el financiamiento de la educación superior. Modelos de asignación de aporte público. 


\section{trabalhonecessário}

issn: 1808-799X

ano 7 - número 8 - 2009

Buenos Aires, Ar: Ministerio de Cultura y Educación, Secretaria de Políticas Universitarias.

SHEEHAN, J. (1995, Abril). Reform of higher education finance: what are the practical issues when implementing change? Washington, D.C.: The World Bank Group, Education Division.

SILVA, P. (1994). Technocrats and politics in Chile: from the Chicago Boys to the CIEPLAN monks. In DRAKE, P.W. (Ed.), Money doctors, foreign debts, and economic reforms in Latin America: from the 1890s to the present. Wilmington, DE: Scholarly Resources Inc.

SIQUEIRA, A. C. (2001). The new economic global order and its effects on higher education reforms. Florida State University/ College of Education. Tese de Doutorado. SKLAR, H. (Ed.). Trilateralism. The Trilateral Commission and elite planning for world management. Boston, MA: South End Press.

UNITED NATIONS - UN (1974). Declaration on the Establishment of a New International Economic Order. Resolution 3201 (S-VI). New York: United Nations, General Assembly, Sixth Special Session.

VALDÉS, J. G. (1995). Pinochet's economists. The Chicago school in Chile. Great Britain, Cambridge: Cambridge University Press.

WILLIAMS, M. (1994). International economic Organisations and the Third World. London: Harvester Wheatsheaf.

WINKLER, D R. (1994) La educación superior en Amércia latina. Cuestiones sobre eficinecia y equidad. (77S). Washington, D.C.: The World Bank (Traduzido do original em inglês de 1990.

WOLFF, L. e ALBRECHT, D. (Eds.).(1992, Novembro). Higher education reform in Chile, Brazil and Venezuela. Towards a redefinition of the role of the State. (A view of the LATHR, 34). Washington, D.C.: The World Bank, Human Resources Division/LACR WORLD BANK. (1994, Maio). Higher education. The lessons of experience. Washington, D.C.: The World Bank Group. Series Development in Practice.

WORLD BANK. (1998). Chile. Higher education improvement project. Human and Social Development Group.(Report $n^{\circ}$ 17887). Washington, D.C.: The World Bank, 
issn: 1808-799X

ano 7 - número 8 - 2009

Argentina, Chile and Uruguay Country Management Unit, Latin America and Caribbean Region. 